\title{
TRANS(FORMAR) O NOME: Alguns Efeitos do Nome Social e da Alteração do Nome Civil na Vida de Sujeitos Trans
}

\author{
Luis Felipe Hatje ${ }^{1}$ \\ Paula Regina Costa Ribeiro ${ }^{2}$ \\ Joanalira Corpes Magalhães ${ }^{3}$
}

\begin{abstract}
RESUMO
O presente artigo tem como objetivo investigar tanto os sentidos do nome social e do nome civil na vida de sujeitos transgêneros quanto alguns efeitos produzidos em suas vidas após a decisão judicial que alterou seus nomes e gêneros nos documentos oficiais. Analisam-se narrativas de quatro homens trans ao longo de entrevistas individualizadas e do acompanhamento de um grupo focal, utilizando-se a metodologia da investigação narrativa. A partir das análises conclui-se que o ingresso no Judiciário representou uma medida necessária para que esses sujeitos pudessem garantir o exercício de alguns aspectos da cidadania que até então lhes eram negados. Além disso, evidenciou-se que, desde a sentença judicial, estes sujeitos passaram a atribuir ao Estado uma fonte de legitimidade e de reconhecimento sobre as suas identidades de gênero. Palavras-chave: Nome civil. Nome social. Transgênero. Educação em gênero e sexualidade.
\end{abstract}

\section{TRANSFORMING THE NAME: SOME EFFECTS OF THE SOCIAL NAME AND} THE AMENDMENT OF THE CIVIL NAME IN THE LIFE OF SUBJECTS TRANS

\begin{abstract}
The article aims to investigate both the meanings of the social name and the civil name in the life of transgender subjects as well as some effects produced in their lives after the judicial decision that changed their names and genres in official documents. In this sense, we analyze narratives of four transsexuals through individual interviews and a focus group, using the methodology of narrative investigation. From the analysis, it was possible to conclude that the entrance in the judiciary represented a necessary measure so that they could guarantee the exercise of some aspects of the citizenship that until then were denied to them. In addition, it has been shown that, since the judicial sentence, these subjects started to attribute to the State a source of legitimacy and recognition of their gender identities.
\end{abstract}

Keywords: Civil name. Social name. Transgender. Education in gender and sexuality.

RECEBIDO EM: 29/1/2019

ACEITO EM: $17 / 4 / 2019$

\footnotetext{
${ }^{1}$ Doutorando em Educação em Ciências pela Universidade Federal do Rio Grande (Furg). Mestrado em Direito e Justiça Social e em Educação em Ciências e Especialização em Abordagem Multidisciplinar em Dependência Química pela Universidade Federal do Rio Grande (Furg). Advogado. Integrante do Grupo de Pesquisa Sexualidade e Escola (Gese). Realizou intercâmbio na Universidade de Coimbra - Portugal. Experiência em projetos de extensão e pesquisa com ênfase em Criminologia, Sistema Penitenciário, Direitos Humanos, Gênero e Sexualidade. http://lattes.cnpq.br/4929788321027336. https://orcid.org/0000-0002-4038-5510. If_hatje@msn.com

${ }^{2}$ Graduação em Ciências - Licenciatura Plena em Biologia (Universidade Federal do Rio Grande - Furg, 1985). Mestrado em Biociências (Pontifícia Universidade Católica do Rio Grande do Sul - PUCRS, 1991). Doutorado em Ciências Biológicas (Universidade Federal do Rio Grande do Sul - UFRGS, 2002). Pós-Doutorado (Escola Superior de Educação de Coimbra/Instituto Politécnico de Coimbra - Portugal, 2015). Professora titular do Instituto de Educação e dos Programas de Pós-Graduação: Educação em Ciências (Associação Ampla Furg/UFRGS/ UFSM) e Educação Ambiental da Universidade Federal do Rio Grande - Furg. Pesquisadora do Grupo de Investigación en Educación y Sociedad - Gies (composto pelas seguintes instituições: Universidad de Castilla-La Mancha, Universidade Federal do Rio Grande - Furg, Universidad de Córdoba, Instituto Politécnico de Coimbra - Escola Superior de Educação). Líder do Grupo de Pesquisa Sexualidade e Escola-Gese, atuando principalmente nos seguintes temas: corpos, gêneros e sexualidades. Bolsista produtividade $1 \mathrm{C}$ do CNPq. http://lattes. cnpq.br/0516745823012125. https://orcid.org/0000-0001-7798-996X. pribeiro.furg@gmail.com

${ }^{3}$ Doutorado em Educação em Ciências (PPG Educação em Ciências: Química da Vida e Saúde - Associação Ampla Furg, UFRGS E UFSM, 2012). Mestrado em Educação em Ciências (UFRGS, 2009). Graduação em Ciências Biológicas - Licenciatura e Bacharelado (Furg, 2006). Pós-Doutorado (UFRGS). Professora-adjunta do Instituto de Educação, do PPG Educação em Ciências: química da vida e da saúde e do PPG Educação (Furg). Pesquisadora do Grupo de Investigación en Educación y Sociedad - Gies (composto pelas seguintes instituições: Universidad de Castilla-La Mancha, Universidade Federal do Rio Grande - Furg, Universidad de Córdoba, Instituto Politécnico de Coimbra - Escola Superior de Educação). Vice-líder do Grupo de Pesquisa Sexualidade e Escola - Furg. http://lattes.cnpq.br/5154939094832400. https:// orcid.org/0000-0002-9785-6854. joanaliracm@yahoo.com.br
} 
As reivindicações dos sujeitos transgêneros são cada vez mais frequentes em diferentes instâncias sociais e têm impulsionado o debate acerca das demandas dos indivíduos que constroem seus gêneros em oposição às expectativas sociais sobre o que é ser homem e o que é ser mulher. Nesse sentido, um dos assuntos que têm ganhado visibilidade são as demandas dos sujeitos transgêneros ao poder Judiciário. Assim, considerando-se que as ações judiciais que envolvem a transgeneridade têm sido cada vez mais frequentes, procura-se, neste texto, contribuir para a discussão acerca do reconhecimento das variadas formas de construção e vivências de identidades de gênero.

Uma das demandas dos sujeitos trans está relacionada à utilização do nome pelo qual se reconhecem. Isto explica o motivo de tantos virem recorrendo ao Judiciário para pleitear a alteração do registro civil e a redesignação do gênero nos documentos oficiais, com o objetivo de exercerem sua cidadania. Tendo em vista que o ordenamento jurídico não dispõe de norma explícita que permita a readequação civil do sujeito transgênero, os pleitos destes indivíduos eram submetidos a decisões que estavam à mercê do entendimento dos(as) juízes/ízas. ${ }^{4}$

Para tanto, acompanhamos quatro sujeitos transgêneros que ingressaram no Judiciário em busca de alteração do registro civil e gênero, ajuizando ações em abril de 2017 e obtendo sentenças favoráveis a partir de outubro do mesmo ano. A partir disto propusemo-nos a investigar, neste artigo, os sentidos do nome social e do nome civil na vida desses sujeitos, bem como alguns efeitos produzidos após a decisão judicial que possibilitou a alteração de seus documentos oficiais.

Assim, acreditamos que esta pesquisa possa contribuir para a educação, na medida em que leva em consideração qualquer conhecimento produzido em um determinado espaço e tempo específicos. Além de que, para que tal conhecimento possa ser compreendido/compartilhado, é necessário atentar-se à trama discursiva à qual estes sujeitos estão vinculados, uma vez que eles podem tomar partido na constituição e na manifestação de uma verdade neste momento.

Nesta investigação valemo-nos das contribuições dos/as autores/as do campo dos Estudos Queer, adotando, por exemplo, a perspectiva de autoras como Judith Butler, sobretudo no tocante às suas provocações relacionadas com as normas heterossexuais e à ideia de performatividade de gênero. Para produção e análise dos dados utilizamos a metodologia de investigação narrativa a partir das teorizações propostas por Jorge Larrosa $(1994,1996)$ e Michael Connelly e Jean Clandinin (1995), autores que discutem a narrativa como uma formação discursiva por meio da qual os sujeitos dão sentido aos fatos e aos acontecimentos narrados. Ademais, conforme argumenta Larrosa (1996), é por meio do processo narrativo que os sujeitos passam a construir a sua história, a dar sentido a quem são e, também, a quem são os outros, constituindo, assim, a sua identidade.

Este artigo foi organizado em quatro seções: na primeira, tecemos considerações acerca do referencial teórico adotado, procurando estabelecer algumas aproximações entre a Teoria Queer e a transgeneridade; na segunda apresentamos, sucintamente, os

\footnotetext{
${ }^{4}$ Em março de 2018 o Supremo Tribunal Federal decidiu que pessoas trans podem alterar o nome e o gênero no registro civil em cartórios, sem que se submetam a cirurgia ou que comprovem sua identidade psicossocial, que deverá ser atestada por autodeclaração (CARTA CAPITAL, 2018).
} 
sujeitos participantes desta pesquisa e a metodologia de produção e análise dos dados construídos; na terceira analisamos os sentidos do nome social e civil na vida dos sujeitos trans entrevistados, bem como as mudanças que esses sujeitos perceberam após a sentença que possibilitou que o nome social passasse a ser o seu nome civil; e, por fim, trazemos, nas considerações finais, alguns apontamentos acerca dos significados que os entrevistados atribuem ao seu nome e como estes estão imbricados a um processo de produção e constituição das suas identidades trans.

\section{TEORIA QUEER E TRANSGENERIDADE}

Considerando que esta pesquisa pretende articular distintos campos de saber relacionados ao direito e ao gênero, procuramos subsídios teóricos para discutir o processo de subjetivação dos sujeitos transgêneros também a partir do processo de construção e legitimação dos seus nomes, indo além dos saberes médicos e biológicos tradicionalmente "acionados" quando esta temática é discutida. Para problematizar as questões relativas aos sujeitos trans (uma discussão que rompe com alguns padrões pré-estabelecidos socialmente), considera-se necessário um aporte teórico que seja capaz de "traduzir" o seu viés contestador. Por isso, optamos por utilizar a Teoria Queer por considerar que ela possibilita um olhar crítico e plural acerca das questões que envolvem os sujeitos transgêneros.

A Teoria Queer emerge como uma corrente teórica que possibilita pensar e questionar as formas correntes de compreensão das identidades sociais (PINO, 2007); pensar as questões trans na sua esteira contribui para que sujeitos transgêneros possam encontrar nela os aportes necessários para o desenvolvimento de um pensamento múltiplo que subverta, questione e pluralize as suas identidades (PINO, 2007), vislumbrando movimento e transformação (PEREIRA, 2008).

Richard Miskolci assevera que "um olhar queer sobre a cultura convida a uma perspectiva crítica em relação às normas e convenções de gênero e sexualidade" (2013, p. 33). Para este autor, a proposta da Teoria Queer é fazer com que aquelas/es que normalmente são excluídos/as socialmente, desclassificados/as e colocados/as à margem do processo educacional e da experiência social, tornem-se visíveis (MISKOLCl, 2011).

A importância dos estudos queer, portanto, reside justamente no que neles há de subversão das identidades de gênero e questionamento da heteronormatividade, ${ }^{5}$ permitindo que se analise mais acuradamente os mais diferentes aspectos relacionados à transgeneridade; o que quer dizer que estes estudos possibilitam, entre outros fatores, que se reflita criticamente sobre as questões que estes sujeitos devem enfrentar em sua empreitada para que sejam reconhecidos pelo gênero com o qual se identificam.

\footnotetext{
${ }^{5}$ Conforme Berenice Bento, a heteronormatividade pode ser definida como "A capacidade da heterossexualidade apresentar-se como norma, a lei que regula e determina a impossibilidade de vida fora dos seus marcos. É um lugar que designa a base de inteligibilidade cultural através da qual se naturalizam corpos/gêneros/desejos, definindo o modelo hegemônico de inteligibilidade de gênero, que supõe que, para que o corpo tenha coerência e sentido, deva haver um sexo estável expresso mediante o gênero estável (masculino expressa homem, feminina expressa mulher) (BENTO, 2012, p. 51).
} 
O gênero configura-se como uma categoria analítica de problematização das concepções de masculinidade e feminilidade que permeiam a sociedade e possibilitam uma ruptura com o sistema binário dos sexos. Para a filósofa Judith Butler (2003):

Quando o status construído do gênero é teorizado como radicalmente independente do sexo, o próprio gênero se torna um artifício flutuante, com a conseqüência de que homem e masculino podem, com igual facilidade, significar tanto um corpo feminino como um masculino, e mulher e feminino, tanto um corpo masculino como um feminino (p. 24).

Neste sentido é que, para Butler (2001, p. 40-41), "essa construção que chamamos de sexo é tão culturalmente construída como o gênero". Para ela, a categoria "sexo" tem como atribuição normatizar os indivíduos, atuando como uma prática reguladora da produção dos corpos aos quais ela (a categoria sexo) controla e governa. Ávila reitera que "Butler chama a atenção sobre a condição não estática de um corpo, pois o sexo, sendo um ideal regulatório, é uma construção ideal que se materializa através do tempo em função da reiteração forçada dessas normas" (ÁVILA, 2014, p. 85).

Para Butler (2005, p. 18), "os corpos nunca acatam inteiramente as normas mediante as quais se impõe sua materialização"; são justamente essas rupturas da normatividade que possibilitam que tais normas regulatórias voltem-se contra si mesmas e coloquem em xeque a força hegemônica das mesmas leis regulatórias, permitindo o surgimento de possibilidades de escape e de (re)materialização dos corpos, sexos e gêneros (BUTLER, 2000).

Em meio a estas rupturas das normas regulatórias, inventam-se meios para que performances subversivas de gênero aconteçam. Segundo Ávila, "as teorias de Judith Butler abriram uma via às novas subversões das normas heterossexuais e à reflexão sobre a performatividade de gênero, iniciando o debate sobre as práticas transgenéricas e as análises dos discursos sobre estas práticas" (2014, p. 30). São os sujeitos transgêneros, portanto, que possibilitam problematizar este sistema binário de masculinidades e feminilidades, de homem e mulher, de heterossexual e homossexual (BENTO, 2006; SANTOS, 2015), ultrapassando os discursos restritivos que insistem no binarismo como única possibilidade, "toma[ndo] a forma de uma operação reguladora de poder que naturaliza o caso hegemônico [a heterossexualidade] e reduz a possibilidade de pensar em sua alteração" (BUTLER, 2006, p. 70-71).

Em síntese, entendemos os sujeitos transgêneros como aqueles sujeitos que possibilitam pensar em algumas rupturas da normatividade hegemônica construída sobre os gêneros, embora estejamos cientes de que, "Queer ou não, estamos todos presos a um conjunto de normas com as quais temos que lidar" (PERREAU, 2018, s/p). ${ }^{6}$

${ }^{6}$ RESISTA! "Queer ou não, estamos todos presos a um conjunto de normas com as quais temos que lidar". Disponível em: https://resistaorp.blog/2018/07/10/queer-ou-nao-estamos-todos-presos-a-um-conjunto-de-normas-com-as-quais-temos-que-lidar/. Acesso em: 15 jul. 2018. 
Neste processo de construção de identidade de sujeitos transgêneros, alguns buscam uma aproximação com as normas ao escolherem um nome que socialmente se adéque ao gênero com o qual se identificam, considerando, assim, que a sociedade delimita e determina quais nomes, comportamentos e atributos podem ser atribuídos aos homens e às mulheres.

Desde o nascimento, damos início a um processo de projeção de comportamentos, atitudes e posturas que se espera de acordo com o sexo, pois "a afirmação 'é um menino' ou 'é uma menina' inaugura um processo de masculinização ou feminilização com o qual o sujeito se compromete" (LOURO, 2013, p. 16). Neste contexto, para que um sujeito seja socialmente aceito, é preciso que se conforme às normas de gênero e sexualidade que lhes são socialmente impostas. Por esta razão, uma das formas de os sujeitos transgêneros se adequarem é escolher um nome que corresponda à identidade de gênero com a qual se identificam.

Nesse processo introduzem-se as demandas jurídicas atreladas a essas problematizações. E é justamente esta situação que vem provocando discussões que envolvem gênero e direito. Verifica-se que, nos poderes Legislativo e Judiciário, leis e ações que envolvem a transgeneridade são cada vez mais frequentes. De modo que se abre, assim, uma agenda de discussões jurídicas no tocante às decisões de reconhecimento das identidades de gênero.

\section{CAMINHOS METODOLÓGICOS: Os Sujeitos de Pesquisa e a Investigação Narrativa}

Com base nestes pressupostos teóricos, pretendemos desenvolver a pesquisa com a contribuição dos Estudos Culturais, principalmente em sua vertente pós-estruturalista. Como estratégia metodológica decidimos utilizar a "investigação narrativa" para a produção e análise dos dados. Ressaltamos que nessa lide também compreendemos que nossos olhares são interpelados ou atravessados por questões que constituem o modo como construímos a nossa pesquisa.

A narrativa tem sido defendida por pesquisadores como Michael Connelly e Jean Clandinin (1995) tanto como um método de investigação quanto como aquilo que se investiga. Para eles, a narrativa "é o estudo da forma em que os seres humanos experimentam o mundo" (CONNELLY; CLANDININ, 1995, p. 11). A partir da leitura destes autores entendemos a narrativa como uma prática social que constitui os sujeitos no processo de ouvir e contar histórias. Este processo de contar histórias vivenciadas faz com que a pesquisa apresente o olhar de quem as conta. Assim, os fatos são recontados não apenas a partir do que aconteceu em algum momento de nossas vidas, mas também refletem as nossas experiências no presente.

Ao longo deste trabalho realizamos entrevistas semiestruturadas individualizadas com quatro sujeitos trans homens, integrantes do grupo "Transformando Vidas". 7 Estas entrevistas foram realizadas em dois momentos diferentes: no primeiro momento, quando ingressaram no Judiciário pleiteando a alteração do nome e do gênero no regis-

O grupo foi constituído a partir de uma rede de apoio a pessoas transgêneras, no sentido de estabelecer relações entre diferentes profissionais que poderiam contribuir com aspectos relacionados à saúde, educação, direitos, acesso à cidadania e a demais questões que permeiam a vida de sujeitos que possuem algumas demandas específicas em razão de sua identidade de gênero. 
tro civil; e, no segundo, alguns meses após a sentença judicial que autorizou a alteração do nome e do gênero nos documentos oficiais, por meio da constituição de um grupo focal com a presença dos quatro sujeitos transgêneros.

Vale dizer, também, que, com o objetivo de respeitar a metodologia de investigação, solicitamos o consentimento dos participantes do grupo, formalizando-o por meio da assinatura de um "Termo de Consentimento Livre e Esclarecido", mediante o qual foi autorizada a entrevista e o uso de seus nomes na pesquisa. ${ }^{8}$ Diante dessas considerações apresentamos, a seguir, um breve relato da história de vida de cada um deles.

Luis Mahin nasceu no dia 7 de dezembro de 1960, branco, autoidentifica-se no gênero masculino e é casado com uma mulher. Na ocasião da entrevista cursava o último ano de Bacharelado em História e era bolsista de iniciação científica do CNPq. Luis utiliza marcadores corporais ditos masculinos, como: prenome, roupas e corte de cabelo, contudo não deseja realizar tratamentos hormonais ou cirurgia de redesignação.

Silvio nasceu no dia 15 de dezembro de 1996, branco, se autoidentificou como homem trans bissexual e, atualmente, namora uma mulher. Já realiza tratamento endocrinológico e pretende realizar cirurgias de mastectomia. Cursa o segundo ano da Graduação em Biologia (Bacharelado).

Noah Mathias nasceu no dia 17 de fevereiro de 1998, branco, autoidentificou-se como transexual masculino bissexual. No momento da entrevista namorava uma menina. É estudante do Ensino Médio. Pretende realizar cirurgias de mastectomia e redesignação.

Lucas nasceu no dia 17 de março de 1996, branco, autoidentificou-se como homem trans e não tem nenhuma definição em relação à sua identidade sexual. Na ocasião da entrevista namorava um menino. Já realiza tratamento endocrinológico e pretende realizar cirurgias de mastectomia, mas não pretende se submeter à cirurgia de redesignação sexual. Cursa o terceiro ano da Graduação em Artes Visuais.

As narrativas que foram construídas durante as entrevistas no grupo focal foram analisadas a partir dos pressupostos teóricos propostos por Jorge Larrosa $(1994,1996)$. Este autor define as narrativas como uma modalidade discursiva, na qual os sujeitos transgêneros entrevistados se constituem a partir de uma rede de discursos para produzir suas identidades e experiências.

No processo de análise das narrativas construídas fixamo-nos nos sentidos do nome social e civil para a vida dos sujeitos da pesquisa, bem como nos efeitos que estes perceberam após a sentença judicial que possibilitou que o seu nome social passasse a ser um nome civil. Para empreender tal objetivo, em um primeiro momento observamos as narrativas produzidas nas entrevistas a fim de compreender os significados do nome social. A posteriori partimos para a análise das narrativas construídas no trabalho conjunto do grupo focal, detendo-nos especialmente nos efeitos do nome civil nessa ocasião.

\section{O NOME SOCIAL "NÃO TEM VALOR NENHUM"}

No Brasil não temos ainda uma legislação específica com relação às demandas relacionadas à identidade de gênero dos sujeitos transgêneros, havendo apenas algumas portarias e regulamentos esparsos sobre determinados temas, como a cirurgia de

\footnotetext{
${ }^{8}$ Os quatro sujeitos entrevistados desejaram e autorizaram, mediante a assinatura do referido termo, a utilização do prenome pelo qual se identificam.
} 
redesignação sexual e, atualmente, a possibilidade de alteração do nome e do gênero dos sujeitos transgêneros, sem a necessidade de intervenções cirúrgicas. Antes da possibilidade de retificação do nome, no entanto, os sujeitos transgêneros necessitavam ingressar no Judiciário, ficando à mercê do entendimento dos tribunais ou recorrendo à carteira de nome social.

A carteira de nome social para pessoas transgêneras é uma inovação brasileira que possibilitou a utilização do nome pelo qual a pessoa quer ser identificada na sociedade, uma vez que o nome de registro não confira com a sua identidade de gênero e possa implicar constrangimento (BENTO, 2014). Quanto a isto, cabe explicar que o nome social é o nome pelo qual os sujeitos transgêneros optam por serem chamados em diferentes espaços sociais, em contraste com o nome nos registros oficiais que não refletem a sua identidade de gênero.

Os entrevistados Noah, Lucas e Silvio narraram que a busca pela confecção da carteira de nome social foi uma medida necessária diante da possibilidade de terem uma identificação com um nome pelo qual se sentiam reconhecidos. Isto deveu-se, sobretudo, por uma coerência desejada entre o nome social e o gênero pelo qual se reconhecem - o que lhes permitiu transitar em diferentes espaços sociais sem serem reconhecidos como indivíduos transgêneros.

Noah: Porque eu não tive nenhuma complicação assim em... ninguém foi contra isso, nem eu tive problema de falar para as pessoas que agora eu tinha outro nome, foi tudo tranquilo, muito rápido, muito fácil. [...] é porque não dá mais para eu ter um nome de registro feminino, sendo que eu sou um homem. Não encaixa mais. [...] eu não consigo mais entregar um documento e falar essa pessoa aqui sou eu, com esse nome aqui entende, não dá mais [grifo nosso] (Entrevistas). ${ }^{9}$

Para Butler (2003) e Goellner (2013), os corpos são construções sociais que vão além daquilo que vemos ou tocamos, mas também são os acessórios, gestos, e aquilo que falamos sobre eles. Segundo Goellner, "não são, portanto, as semelhanças biológicas que o definem, mas, fundamentalmente, os significados culturais e sociais que a ela se atribuem." (2013, p. 31). De igual modo, o nome também é uma construção social, por meio da qual a linguagem é utilizada para atribuir uma série de significados sobre os corpos e vidas dos sujeitos, possibilitando a sua maior ou menor inserção social. Por essas razões, a possibilidade de utilização de uma carteira social em que conste o nome socialmente atribuído a homens produz, de antemão, alguns efeitos sobre esses sujeitos, uma vez que, com a adoção de um nome masculino, eles se sentem mais confortáveis para incorporar outros marcadores deste gênero às suas identidades.

Em sua narrativa, Lucas afirmou que, depois de se reconhecer como sujeito masculino, iniciou seu processo de transição a partir da mudança de seus documentos de identificação e do tratamento hormonal:

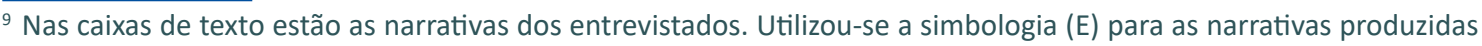
a partir das entrevistas e (GF) para as narrativas produzidas no grupo focal. 
Lucas: [...] A primeira coisa que eu fui focando foi a parte de documentação e a parte hormonal. Eu fiz a minha carteirinha de nome social, mudei o nome social aqui da Furg, aí fui tentando mudar toda a documentação, consegui mudar a conta de luz que pode, tudo que pode usar nome social, nome no banco, no cartãozinho, no SUS, carteirinha de médico, de convênio médico, tudo assim eu fui atrás, mas ainda existe muita barreira pelo fato do meu $R G$, contrato de aluguel, no próprio CPF, FGTS, PIS, eu não posso usar o nome que eu realmente me identifico como Lucas por causa do RG, que tá o nome que meus pais me deram [grifo nosso] (E).

Durante esse processo de utilização do nome, Lucas solicitou seus documentos de acordo com as suas demandas cotidianas, e não só realizou a mudança da carteira de nome social como promoveu um movimento para que esta mudança se estendesse também a outros espaços, como a universidade, o Sistema Único de Saúde, a companhia de seu seguro de saúde e o banco. Em determinado momento, entretanto, essas alterações foram barradas devido ao fato de a carteira de nome social não ser considerada um documento válido.

As limitações da carteira social justificam o motivo de Luis ser o único, entre os quatro entrevistados, que não confeccionou o documento social. Segundo ele, ela não possuiria validade suficiente se não fosse acompanhada de outro documento que endossasse a sua legitimidade. Por isso, para ele, a carteira social "não [tinha] valor nenhum":

Luis: [...] eu não tenho carteira social, não vou fazer, porque na realidade a carteira de nome social ela não tem valor nenhum, porque se eu não tiver um documento pra endossar, pra comprovar que aquele documento é meu, continua, não altera nada, é impossível tu pensar que nesse momento que tem tanta política pública que tu tem que comprovar que aquele documento não é falso. [...] essa carteira eu sempre fui contra. Quando eu comentei sobre isso, e eu sempre critiquei o nome social naquela carteirinha, aquilo foi o Estado que criou, alguém que criou, eu sei que são políticas públicas, mas são políticas públicas que acabam não tendo o efeito que deveriam ter, porque se eu tenho que apresentar uma carteira de nome social com o RG para ela ser válida, é pura gambiarra (E).

Santos (2015, p. 633) explica que a carteira de nome social é "um documento físico semelhante à carteira de identidade comum, com valor de registro civil, que traz a inscrição do nome social e o número do registro geral de travestis e transexuais". Esse documento, contudo, não tem evitado que esses sujeitos sejam submetidos a situações constrangedoras diante da impossibilidade de utilização da carteira de nome social sem que outros documentos oficias com o nome de registro sejam igualmente apresentados. Silvio e Noah explicam a situação:

Silvio: [...] quando eu apresento o cartão social, quando eu vou para algum lugar as pessoas pedem o RG, aí eu tenho que ter o constrangimento de mostrar aquela pessoa que não sou eu, que está lá no RG, porque o cartão social ainda não é tão aceito [grifo nosso].

Entrevistador: Muita gente fala que quando apresenta a carteira de nome social eles pedem junto a carteira de identidade também? 
Noah: Sim. Então acaba que não vale de nada, mas dependendo das informações que eles pedem eu já mostro a carteira de nome social e já falo as outras informações para não ter que entregar a identidade, mas sempre pedem a outra (E).

Os sujeitos narraram também que em razão dessas limitações do documento social, frequentemente eles evitavam transitar em espaços nos quais não eram/são reconhecidos ou que pudessem/possam vir a ser vítimas de constrangimento. Algumas vezes isso acontece por desconhecimento dos profissionais que atendem em determinados espaços. Por outro lado, não se pode descartar o intuito de muitos de agir para deslegitimar o reconhecimento e o direito adquirido das pessoas trans. Noah narrou que, mesmo solicitando a utilização do nome social, algumas pessoas the chamaram pelo nome de registro:

Noah: Eu evito ir ao hospital e ir no médico desde que eu comecei a transição, porque eu não quero passar por nenhuma situação constrangedora, mas houve vezes que eu tive que ir e me chamaram no nome de registro, mesmo eu pedindo $o$ nome social [grifo nosso] (E).

Outra questão apontada por Lucas é a inviabilidade da utilização da carteira de nome social fora da jurisdição na qual ela é confeccionada: ele reside e estuda no Rio Grande do Sul, ${ }^{10}$ emitiu o documento nesse Estado, mas quando vai até São Paulo, onde residem seus familiares, não pode utilizar o documento, por exemplo, a partir de sua chegada ao aeroporto:

Entrevistador: E nesse sentido, a carteira de nome social que tu tens não tem dado conta?

Lucas: Não, com certeza não tem dado conta, porque, por exemplo, se eu for pra São Paulo, vale aqui no Rio Grande do Sul, até tá escrito lá certinho que só é válido aqui para o Rio Grande do Sul, se eu for pra São Paulo a coisa fica mais difícil porque não vale, se eu for pra outro país, também vai ficar difícil a parte burocrática porque não vale, sabe, então é terrível, é terrível não ter o nome certo que é Lucas, e ter que ser chamado de [nome de registro], às vezes as pessoas ficam me olhando: "mas é homem ou mulher", não sabe dizer porque nem eu consigo me ver, eu falo: "Esse nome saiu errado na certidão", eu até às vezes tento falar isso porque não consigo mesmo... (E)

Conforme dados fornecidos pela Associação Brasileira de Gays, Lésbicas, Bissexuais, Travestis e Transexuais (ABGLT), ${ }^{11}$ existem iniciativas relacionadas ao nome social nos Estados do Amapá, Minas Gerais, Amazonas, Piauí, Pará, Goiás, Paraná e Rio Grande do Sul, contudo a validade do documento está adstrita à jurisdição de cada Estado. Em caso de deslocamento para outros Estados, como explica Lucas, o documento deixa de ter validade.

\footnotetext{
${ }^{10}$ No Estado do Rio Grande do Sul instituiu-se a Carteira de Nome Social para Travestis e Transexuais com o Decreto 49.122, de 17 de maio de 2012, publicado no DOE no 096, de 18 de maio de 2012. A CNS é válida para tratamento nominal nos órgãos e entidades do poder Executivo do RS.

${ }^{11}$ Disponível em: http://www.estadosecapitaisdobrasil.com/duvidas/o-que-e-nome-social/. Acesso em 16 maio 2018.
} 
Santos (2016, p. 112) explica que "as denúncias relativas ao desrespeito ao nome social são constantes e dificilmente resolvidas. A complexidade envolve a falta de consenso mesmo entre a esfera política: alguns deputados estão trabalhando para revogar o decreto assinado pela presidente, ${ }^{12 "}$ que possibilitava a utilização do nome social no âmbito da administração pública federal direta, autárquica e fundacional. Assim sendo, além do embate entre forças políticas contrárias e favoráveis à utilização do nome social, verifica-se também que este nome só tem legitimidade jurídica em uma microesfera, considerando-se que ele só é reconhecido em repartições públicas, em algumas universidades e em bancos de alguns Estados do Brasil (BENTO, 2014).

Lucas explica que, embora tenha vários documentos com o seu nome social, não conseguia mais ver o seu nome de registro presente em seus documentos de identificação, pois acreditava que não estavam corretos. Para ele, por mais que o seu corpo the cause incômodo, o seu nome de registro lhe causava ainda mais desconforto, por isso ele considera que o nome é essencial para a identificação dos sujeitos:

Lucas: [...] eu não quero esse nome, eu evito de todas as formas possíveis... eu não consigo nem olhar para esse nome porque o meu corpo, como eu falei, ele me causa incômodo, mas, com certeza, o nome me causa muito mais, porque é como as pessoas realmente me identificam, nome é nome, nome é essencial, antes do corpo, o que vale mesmo é o teu nome que eu vejo [grifo nosso] (E).

Com relação à utilização do nome de registro, Bento (2006, p. 57) explica que "o nome próprio aqui funciona como uma interpelação que o recoloca, que ressuscita a posição de gênero da qual luta para sair". Por esta razão, "serem identificados/as publicamente pelo nome que os/as posiciona no gênero rejeitado era uma forma ressignificada de atualizar os insultos de "veado", "sapatão", "macho-fêmea", que, ao longo de suas vidas, os/as haviam colocado à margem" (BENTO, 2006, p. 57).

Por meio das narrativas constatou-se que a carteira de nome social tem uma amplitude de utilização limitada, não produzindo todos os efeitos práticos desejados, o que, não raramente, traz constrangimentos às pessoas trans. Não por acaso, os quatro sujeitos entrevistados optaram por ingressar no Judiciário para pleitear a retificação do nome e do gênero nos seus documentos oficiais.

Silvio acredita que ter todos os seus documentos em conformidade com a sua identidade de gênero é seu direito, portanto, ingressar no Judiciário foi um modo de conquistar um reconhecimento pessoal, social e jurídico acerca da sua identidade de gênero:

Entrevistador: Que motivos então te levaram a tu ingressar na Justiça pra mudar o nome?

Silvio: A possibilidade de poder ingressar pra trocar o nome é um direito que eu já sabia, só não tinha acesso antes porque eu achava que não conseguiria ganhar o processo... então eu esperei ter a segurança pra conseguir e agora com isso, ter o meu RG me representando eu acho que vou pendurar ele assim e vou sair nos luga-

\footnotetext{
${ }^{12}$ A presidente da República Dilma Rousseff assinou, em 28 de abril de 2016, o Decreto $n^{\circ} 8.727$ que "dispõe sobre o uso do nome social e o reconhecimento da identidade de gênero de pessoas travestis e transexuais no âmbito da administração pública federal direta, autárquica e fundacional".
} 
res: "não, finalmente eu sou eu". [...] o nome é um reconhecimento muito grande e eu acho que vou ficar olhando para o RG por horas, "não, sou eu", finalmente eu sou um ser social agora, eu me sinto bem agora (E).

Para Noah, a carteira de nome social não contemplava suas necessidades. A retificação de seus documentos oficiais também tem a ver com uma preocupação com o futuro, uma vez que ele deseja se casar e ter filhos/as e espera que o seu nome retificado conste na certidão de casamento, nos documentos dos seus/suas futuros/as filhos/as, em um diploma, etc.

Noah: [...] eu quero me casar, eu quero que meu nome vá pra certidão de casamento, eu quero que os meus filhos tenham o meu nome na identidade deles, sabe, eu quero tudo isso. Pra mim e pro meu futuro, [...] porque o nome social é uma carteirinha que eu posso usar em tal coisa, tal coisa, mas tendo no registro o teu nome que tu te identifica é bom demais, aí tem passaporte, tem carteira de trabalho, tu tem que entregar com o nome de registro, né, tu tem que fazer tudo com nome de registro, as pessoas já te tratam diferente por causa [disso], por verem o nome de registro... então eu acho que vai mudar tudo, eu não vou precisar mais ter que dar explicação da minha vida pra todo mundo, não vou precisar explicar o que é um nome social, entendeu, não vou ter que me abrir pra todo mundo, eu vou falar meu nome é Noah Mathias, vai tá no registro e pronto, entende (E).

Para esses sujeitos, o reconhecimento dos seus nomes representa a perspectiva de um futuro melhor, evitando rejeições e situações vexatórias. Como salienta Bento, "o nome próprio de batismo pronunciado publicamente produz uma descontinuidade entre esse nome e as performances de gênero" (2006, p. 58), por isso o nome retificado nos documentos oficiais possibilitará seu reconhecimento como sujeito masculino.

As análises a seguir discutem alguns efeitos produzidos em suas vidas após a possibilidade de alterar seus documentos oficiais e como essa mudança foi constituindo esses sujeitos como homens transgêneros.

\section{A BUSCA POR RECONHECIMENTO POR MEIO DO NOME CIVIL}

No processo de reconhecimento dos sujeitos trans, diferentes demandas surgem de acordo com aspectos relacionados à subjetividade de cada indivíduo. Nesse processo, alguns sujeitos vão reivindicar modificações corporais, entre as quais incluem-se eventualmente as cirurgias e/ou tratamentos hormonais. Para alguns desses sujeitos, no entanto, tais procedimentos não têm tanta importância, uma vez que consideram que:

A genitália, nesses casos, não é um lugar saturado de significados para as suas sexualidades ou existências. A sexualidade está deslocada radicalmente do órgão reprodutor. $O$ pênis e a vagina estão ali, fazem parte do seu corpo, não se constituindo um locus de produção de conflitos (BENTO, 2006, p. 233).

De igual modo, sobre a alteração do nome e dos documentos, diferentes leituras podem ser realizadas, posto que, assim como o corpo, o nome e os documentos são construídos a partir de um processo histórico e cultural que atribui determinados gêneros para determinadas práticas e artefatos: o masculino não se limita ao pênis; o feminino não se limita à vulva. 
A coerência entre sexo, gênero e sexualidade - culturalmente constituída para estabelecer normas quanto aos gêneros e à[s] sexualidade[s] - delimita que comportamentos são socialmente aceitáveis para homens e mulheres. Não raramente este fator acaba induzindo que indivíduos transgêneros desejem uma equivalência entre o gênero com qual se identificam e um nome que seja associado a este gênero. E isso porque fugir à norma Ihes conferiria um locus de marginalização. Segundo Bento,

os documentos com o nome próprio de acordo com o gênero identificado, as mudanças corporais pelo uso dos hormônios e algumas técnicas para conseguir uma estética considerada apropriada são transformações suficientes para lhes garantir um sentido de identidade [...] A identidade legal de gênero, então, é a principal reivindicação (2006, p. 233).

Ou seja, nesse processo identitário alguns sujeitos buscam se identificar com o gênero pelo qual se reconhecem por meio de uma série de procedimentos, entre os quais a retificação do nome nos documentos possui um impacto relevante. Para Stuart Hall, identidade significa

o ponto de encontro, o ponto de sutura, entre, por um lado, os discursos e práticas que tentam nos "interpelar", nos falar ou nos convocar para que assumamos nossos lugares como os sujeitos sociais de discursos particulares e, por outro lado, os processos que produzem subjetividades, que nos constroem como sujeitos aos quais de pode falar (2000, p. 111-112).

Nessa perspectiva, as identidades não são fixas nem estáveis e são definidas socialmente por meio de um processo de significação, estando, portanto, sujeitas ao poder (SILVA, 2007). Assim, pode-se entender que esse processo de constituição identitária vai sendo forjado ao longo da vida dos sujeitos, enquanto a sociedade também vai atuando de forma a delimitar as formas possíveis de sua constituição, inclusive no tocante aos nomes que são socialmente aceitos para homens e mulheres.

Neste processo de constituição dos sujeitos, segundo Butler (2003), o gênero pode se constituir como uma forma de regulação social, na qual diferentes dispositivos de regulação específicos são utilizados com o objetivo de refletir sobre a maneira como eles são engendrados e impostos aos sujeitos. Entre eles encontra-se o poder médico, "que se supõe o detentor da verdade última sobre os corpos dos sujeitos", e o saber jurídico, que vai "apontar os limites das categorias construídas socialmente para posicionar os sujeitos" (BENTO, 2006, p. 234).

Em razão das limitações impostas pelo saber jurídico, os entrevistados, ao ingressarem no Judiciário pleiteando a retificação de seus documentos, informaram que estavam cientes de que seus pedidos poderiam ser indeferidos pelos órgãos julgadores. ${ }^{13}$

Durante as reuniões do grupo focal discutimos esta possibilidade, uma vez que não havia no Brasil uma uniformidade sobre as decisões acerca das demandas das pessoas trans. Em pesquisa realizada no Estado do Rio Grande do Sul, constatou-se que:

\footnotetext{
${ }^{13} \mathrm{Na}$ ocasião em que os sujeitos participantes desta pesquisa ingressaram no Judiciário, o Supremo Tribunal Federal ainda não havia votado acerca da possibilidade de sujeitos trans alterarem o nome e o sexo no registro civil, sem que fosse necessário que se submetessem à cirurgia de redesignação sexual, em cartórios de registro de pessoas naturais.
} 
Muito embora, num primeiro momento, possa se afirmar que a maioria dos pedidos de alteração do prenome e gênero estão sendo deferidos pelo Tribunal de Justiça do Estado do Rio Grande do Sul, devemos atentar para a maneira como os pedidos são concedidos. Há relativização teórico-conceitual nos argumentos que condicionam a alteração à realização da cirurgia, bem como um apego à normatização binária da temática de gênero e das sexualidades (FLORES; DIAS; BRUM, 2017, p. 52).

Por conseguinte, parte das sentenças que vinham sendo proferidas condicionaram a alteração do nome à obrigatoriedade da cirurgia de redesignação sexual, fazendo valer uma lógica binária no tocante aos gêneros.

Com relação aos quatro sujeitos entrevistados, suas sentenças foram todas favoráveis pela mudança de nome e gênero no assento de nascimento, ${ }^{14}$ sem a necessidade de cirurgia de redesignação sexual. Na decisão judicial considerou-se que "não é a cirurgia que define a pessoa transexual, mas sim a sua identificação com o gênero oposto ao seu sexo biológico". ${ }^{15}$ Nestes casos, a sentença não se vinculou a determinismos biológicos, antes, atentou-se para a vontade de possibilitar que Lucas, Luis, Silvio e Noah Mathias utilizassem em seus documentos um nome socialmente delimitado para o gênero com o qual se identificam: os nomes que escolheram.

Por ser uma demanda que tem efeitos inestimáveis em suas vidas, Lucas, Luis, Silvio e Noah Mathias relataram um sentimento de grande entusiasmo e realização quando souberam da notícia da sentença judicial e, depois, quando receberam seus documentos retificados.

Para Lucas, a obtenção dos documentos retificados melhorou sua autoestima, contribuindo para a superação de uma depressão que foi desencadeada no início do processo de transição de gênero e permitindo-Ihe adquirir mais confiança nas suas relações sociais.

Lucas: Tem muito a ver, os documentos são aquilo que te prova o nome, parece que é algo assim muito importante o nome e mudou muito a minha postura, o que eu percebi... principalmente que eu consegui sair daquela depressão que eu tava, bem do início da transição para agora... a forma de olhar a pessoa, a forma de postura... isso transparece uma confiança para as pessoas, tanto que hoje em dia eu percebo que as pessoas param mais para me ouvir, sabe, as pessoas conseguem me ouvir (GF).

No caso de Luis, além dos documentos de identificação, houve a necessidade de alterar a sua certidão de casamento, pois já era casado antes de ingressar no Judiciário. Para ele, a mudança no nome tem um viés político, uma vez que isto pode mostrar para outras pessoas em situação semelhante que há de fato uma possibilidade de retificação de seus documentos.

\footnotetext{
${ }^{14} \mathrm{Na}$ sentença dos entrevistados constou que no livro cartorário deveria ficar à margem do registro de prenome que a modificação foi procedida de decisão judicial, sem mencionar as razões e conteúdo e que todas as informações relativas ao processo deveriam ser arquivadas em caráter de segredo de Justiça, vetado fornecimento de qualquer certidão para terceiros acerca da situação anterior dos sujeitos.

${ }^{15} \mathrm{~A}$ sentença só foi disponibilizada para as partes do processo, diante do caráter de segredo de Justiça.
} 
Luis: Foi direto na certidão de casamento. Porque quando eu casei eu já perdi a [certidão] de nascimento, então a primeira mudança na minha vida já foi essa [...] eles trocaram o nome, trocaram o gênero, agora eles trocaram o documento, as pessoas casam e automaticamente elas já trocam um documento [...] os documentos que eu tinha eu já incinerei todos, eu não tenho mais documento antigo, então fica muito isso, as pessoas têm isso que às vezes se impactam, mas eu penso que é muito isso, eu sempre acredito nessa questão da política, e eu tenho feito isso (GF).

Sentimento semelhante foi vivenciado por Noah, que disse que a sensação que teve no momento em que recebeu os documentos foi de realização e alívio. Segundo ele, a partir desse momento as pessoas não poderiam mais chamá-lo pelo nome de batismo, dado que agora seu nome estava "certo".

Noah: [...] o que eu senti na hora, tipo... que foi de realização: "tá, isso aqui é o que eu sempre quis", isso aqui é bom, sabe, ter um nome masculino e ter um nome certo, pode mostrar para todo mundo e ninguém mais vai poder te chamar pelo nome de batismo, isso já é um alívio enorme porque tu tá dentro da lei, tu tá dentro das normas que as pessoas esperam ter [grifo nosso] (GF).

A partir do relato de Noah é possível perceber o quanto esses sujeitos têm consciência de como um nome em consonância com o gênero pelo qual se reconhecem pode aproximá-los de uma normatividade socialmente esperada. Ou seja, em alguma medida, a partir da retificação, eles podem ser aproximados da norma binária de gênero, pois têm um nome masculino em um corpo que já vêm buscando ao adotarem também outros atributos ditos masculinos.

A busca por "gêneros inteligíveis" faz com que outras formas de vivenciar o gênero, os corpos e as sexualidades acabem sendo colocadas à margem ou compreendidas como anormais, considerando que "não se conformam às normas da inteligibilidade de gênero" (BUTLER, 2003, p. 39). Assim, "a matriz cultural por intermédio da qual a identidade de gênero se torna inteligível exige que certos tipos de 'identidade' não possam existir - isto é, aquelas em que o gênero não decorre do sexo e aquelas em que as práticas do desejo não 'decorrem' nem do 'sexo' nem do 'gênero'”' (BUTLER, 2003, p. 39).

Isto acontece porque atos e discursos desviantes da matriz heteronormativa encontram pouco ou nenhum espaço na sociedade. Como destaca Louro (2004, p. 66), "os sujeitos que, por qualquer razão ou circunstância, escapam da norma e promovem uma descontinuidade na sequência serão tomados como 'minoria' e serão colocados à margem das preocupações de um currículo ou de uma educação que se pretenda para a maioria".

Essa questão do reconhecimento de suas identidades de gênero também atua na subjetivação desses sujeitos, considerando que, a partir desta sentença judicial, o Estado passa a legitimá-los como sujeitos do gênero masculino - o que, em alguma medida, facilita o seu reconhecimento social e pessoal.

Para Luis, a mudança do nome possibilitou que seus documentos fossem aceitos em diferentes espaços sociais sem que lhe fosse exigido apresentar outros documentos pessoais, posto que, diferente da carteira de nome social, seus documentos foram modificados sem nenhuma informação acerca da condição trans. 
Luis: Eu já chego e falo assim: tá aqui o meu documento oficial, então não tem nem o que reclamar, não tem o que colocar, não tem nada mais para acrescentar... é o meu nome e ponto final, eu levo o documento, levo o RG, levo o título, levo todos os documentos, já estão com a retificação do nome e de gênero, então eu penso que é bem importante fazer isso, e eu penso também que é bem tranquilo, porque esse sujeito se obriga porque ele não vai perguntar se tá no documento oficial como que eu vou dizer que não existe, não tem essa possibilidade (GF).

Um dos impasses que Luis teve após a retificação de seus documentos ocorreu na ocasião da retirada de seu diploma universitário; no diploma constava a averbação "uso do nome social", mesmo que ele já estivesse utilizando o nome civil alterado judicialmente, entretanto a questão foi facilmente solucionada no espaço universitário, em que já fazia o uso do nome pelo qual se reconhece.

Luis: [...] quando eu chego na Furg para tirar o documento aí atrás tem um carimbo: "uso de nome social", só um pouquinho, houve um equívoco aqui, mas só um pouquinho, "não, eu tô com o nome civil desde dezembro, eu já tô em janeiro!", "a gente vai ver se consegue", eu disse: "não, vocês conseguirão, porque vocês tão brincando comigo, com a minha vida", isso aqui é um documento oficial (GF).

Com relação ao reconhecimento social, Butler afirma que "a condição discursiva do reconhecimento social precede e condiciona a formação do sujeito: não que isso confira o reconhecimento de um sujeito; o reconhecimento forma esse sujeito" (2005, p. 317). Assim, o reconhecimento de suas identidades possibilita a produção da subjetividade trans, atuando na constituição desses sujeitos.

Noah e Lucas afirmaram que quanto tiveram o reconhecimento do Estado com a retificação de seus documentos, algumas pessoas de suas famílias e trabalho passaram a lhes reconhecer prontamente, conferindo-Ihes, inclusive, predicados como "força" e "virilidade", atributos que, para o senso comum, são considerados masculinos. Esta atribuição dá provas de que tais predicados não estão vinculados necessariamente ao sexo, mas à construção social em torno do que se considera homem e mulher. Louro discorre a respeito:

É necessário demonstrar que não são propriamente as características sexuais, mas é a forma como essas características são representadas ou valorizadas, aquilo que se diz ou se pensa sobre elas, que vai constituir, efetivamente, o que é feminino ou masculino em uma dada sociedade e em um dado momento histórico [...] importa observar não exatamente seus sexos, mas sim tudo o que socialmente se construiu sobre os sexos (LOURO, 2008, p. 21).

Sendo assim, em seus espaços de convívio, passou-se a exigir de Lucas, Luis, Silvio e Noah Mathias que carregassem signos ou desempenhassem atividades "masculinas", conforme as narrativas:

Noah: O meu pai começou a me tratar no masculino depois do documento.

Lucas: Foi a mesma coisa comigo, até no trabalho, as pessoas me tratam realmente como homem, vamos dizer assim, tipo, aquela coisa, escola espartana.

Noah: Agora tu é um menino. Na verdade a minha sogra começou a me pedir coisas para mim (sic) que ela não pedia antes, por exemplo, "me ajuda a carregar isso aqui" [...] Tenho que fazer mais força do que antes. 
Lucas: Da última vez que eu fui, também meu pai, nossa, meu pai me deu uma caixa, aquela caixa, sabe, quando vai fazer cesta básica e é a cestona, e ele: "carrega isso aqui pra mim", e eu "ok", e ele: "quero ver se você tá bom porque na próxima tu vai bater laje", no trabalho também o pessoal usa aqueles tripés muito grandes e equipamento de filmagem que é muito pesado, aí às vezes os motoristas que vêm aqui da prefeitura perguntam: "Mas isso aqui não é muito pesado para você"?, eles: "não, não, ele aguenta". É legal nesse sentido que as pessoas tão me tratando normal [Grifo nosso] (GF).

Segundo afirmam, após a sentença judicial, na maioria dos espaços eles passaram a ser reconhecidos como homens, no entanto algumas das vezes esse reconhecimento não foi como o desejado, sobretudo em algumas relações familiares. Silvio, por exemplo, explica que sua mãe ainda tem dificuldades ou desconforto para chamá-lo pelo seu nome.

Pesquisador: E ela consegue te chamar de Silvio já?

Silvio: Não, às vezes ela consegue me chamar de gurizinho. E o resto das palavras ela tenta não por gênero, sempre ser o mais neutra possível.

\section{$[\ldots]$}

Silvio: Eu vim mostrando para minha mãe os documentos, fazendo desde o acompanhamento hormonal, eu já tava fazendo de ir conversar com ela, os documentos, quando eu cheguei com a certidão, quando eu cheguei com o RG, fui mostrando para ela e a gente tá tendo mais espaço para dialogar, mas eu tenho mais espaço para falar, só que ela ainda não tá confortável o suficiente para me responder, para ela dizer o que ela pensa sobre isso [...] (GF).

Situação semelhante é vivenciada por Noah, cuja mãe ainda tem restrições quanto a chamá-lo pelo "novo" nome, enquanto o pai, a madrasta e a irmã não encontram nenhuma dificuldade nisso:

Pesquisadora: Mas tu acha que a certidão fez uma mudança para a tua mãe?

Noah: Agora ela tenta um pouquinho mais não falar no feminino, mas também não fez muita diferença não, ela ainda acha que o outro nome ainda vale e todas essas coisas assim.

Pesquisador: E na tua família?

Noah: Na família todo mundo ficou de boa. Agora a madrasta e a irmã não falam mais o outro nome, esqueceram, o pai parou de falar o outro nome também de batismo, tenta ao máximo (GF).

No caso de Silvio, ele vem buscando uma reaproximação com a mãe, procurando estabelecer um diálogo acerca da sua identidade de gênero. Em sua concepção, o não reconhecimento pode estar relacionado não apenas a aspectos biológicos, mas também ao fato de o seu nome agora ser idêntico ao de seu pai, com quem não tem convívio.

Pesquisador: Na tua cabeça, quais os motivos que ela tem dificuldade de falar Silvio?

Silvio: Ela me justificava muito pela questão do biológico. Até eu trazer os documentos. Aí ela começou a me tratar de "gurizinho", mas não pela questão do nome. Mas a questão do nome ficou idêntico ao do meu pai, então isso também pode ter um enorme receio para ela (GF). 
Por outro lado, Silvio também relatou que, a partir do momento em que teve acesso aos documentos alterados, as pessoas deixaram de ter dúvidas sobre a sua identidade de gênero:

Silvio: Muito, muito, não tenho dúvidas, quando eu entrego o documento [as pessoas] não têm dúvida nenhuma sobre mim, porque eles olham o documento, entregam de volta e o tempo todo me tratando no masculino, e também um pouco por conta do hormônio, que já alterou o corpo e a voz, já tem mais uma passabilidade, mas o documento em si, poder entregar ele e ser recebido, de forma certa, é sem palavras (GF).

Assim sendo,, Silvio atribuiu também a aceitação do documento à passabilidade que vem adquirindo por meio de terapia hormonal. Ao adquirir características físicas que correspondem à sua identidade de gênero, isto lhe possibilita transitar em diferentes espaços sem ser identificado como sujeito transgênero. Tiago Duque (2013) relaciona o conceito de passabilidade às concepções de performatividade de gênero, uma vez que diz respeito ao processo pelo qual os sujeitos procuram produzir a expressão de um gênero com o qual se identificam. Segundo Santos, "talvez esse exercício diário de convencer, isto é, de se fazer inteligível em relação à performance de gênero, esteja atrelado à tentativa de escape do espectro da abjeção" (SANTOS, 2015, p. 647). ${ }^{16}$ Neste sentido, o nome também tem um papel importante no processo da passabilidade. Correa observa a respeito:

O nome adentra esse universo de transição também como um elemento importante da passabilidade, na medida em que seus sentidos são geralmente generificados. Além do gênero, o nome geralmente é marcado pela tradição local, significados de família e rituais de sucessão (2017, p. 238).

O reconhecimento social da transição de gênero também confere outros atributos negativos relacionados ao gênero com o qual as pessoas trans se reconhecem, de modo que homens trans podem ser acusados de machismo. Lucas, por exemplo, percebeu que as pessoas, além de o reconhecerem mais como homem, também começaram a lhe incluir em um ambiente em que comportamentos e práticas machistas são reiteradas e consideradas legítimas:

Lucas: [...] uma coisa também que eu percebi no ambiente de amigos em geral, é muito louco, pois as pessoas tão me tratando mais como homem, vamos dizer assim, comportamento, envolve o mundo machista, uma coisa de que, vamos dizer assim, não tão mais me tratando como uma guria, agora é muito louco, foi realmente depois da decisão, eu apresentei os documentos, o pessoal viu assim que o negócio tava sério e as pessoas agora, é incrível porque não tem muito essa coisa de me tratar como guria, sabe. O comportamento da sociedade que eu fiquei, uau, agora parece que eu comecei a entender como que é, quem é identificado como menino desde nascer, passa até pelos bullying (GF).

\footnotetext{
${ }^{16}$ Para Butler, "corpos abjetos são aqueles que se relacionam com tipo de corpos cujas vidas não são consideradas 'vidas' e cuja materialidade é entendida como 'não importante'"' (BUTLER, 2002, p. 161). 
É interessante perceber que Lucas atribui o comportamento machista ao fato de ser reconhecido como homem, pois, antes da sentença judicial, essas práticas não eram tão presentes em sua vida, a ponto de ter se surpreendido com elas. Esta mudança de comportamento das outras pessoas para com ele também é notada em espaços detentores de determinados saberes, como ele identifica na sua relação atual com o seu psicólogo:

Lucas: Mudou um pouco até com o psicólogo pra mim, parece que ficou mais fácil dele tratar no masculino, comportamento, gestos e tal, do que é ensinado para ser masculino, então eu vejo que tem até isso, tipo... ficava mais assim com certo receio, sabe (GF).

Nesse sentido, pensamos na influência dos saberes científicos na vida dos sujeitos e, neste caso específico, de um saber atuando sobre o outro, pois o discurso jurídico passou a atuar sobre as práticas do psicólogo de Lucas. Segundo Roger Raupp Rios e Rosa Maria Rodrigues de Oliveira, "os processos de construção dos sujeitos são compostos pelo discurso jurídico como um de seus elementos mais impactantes, de modo especial quando estão em jogo noções de gênero e sexualidade" (RIOS; OLIVEIRA, 2012, p. 251). No caso específico destes sujeitos, reitera-se o quanto a emanação de um discurso do Estado por meio do poder Judiciário passa a atuar sobre as suas vidas.

Assim, de modo geral, as narrativas apontaram para o sentido de que a alteração do nome foi um marco decisivo para Lucas, Luis, Silvio e Noah Mathias. Nas palavras de Lucas, "o documento me ajudou mais assim na questão de reconhecimento porque dava uma certa crise de identidade quando eu olhava o documento com um nome que eu não me reconhecia". Já Noah, embora a retificação dos documentos tenha lhe causado satisfação, acredita que não foi algo que tenha alterado profundamente sua vida.

Pesquisadora: O Lucas e o Silvio mostraram que isso foi decisivo...

Noah: Pra mim não foi decisivo, não foi, pra mim foi assim uma coisa tipo que acabou acontecendo.

Pesquisador: Tu ficou feliz naquele momento que tu recebeu a certidão...

Noah: É, fiquei feliz, mas depois, segue o baile, tudo normal (GF).

Noah considera que há mais pendências em sua vida no tocante ao seu processo de transição, como o desejo de realizar cirurgia de redesignação sexual, hormonização e acompanhamento psiquiátrico, além de sua preocupação com a conquista de um emprego e a realização um curso superior.

Noah: Porque [...] eu não acho que nome ou qualquer coisa do tipo possa aumentar a minha autoestima.

Pesquisadora: O que pode aumentar a autoestima do Noah?

Noah: Um psiquiatra bem formado.

Pesquisadora: Por que tu achas? Ele vai te receitar um medicamento? Mas tem outras coisas na tua vida? 
Noah: Um emprego. Um emprego. Eu preciso de um emprego. [...] Mas eu acho que a coisa que mais ia ajudar na minha autoestima seria fazer o curso que eu quero, de primeira, teatro, isso ia ajudar na minha autoestima. A minha intenção é fazer um grupo de teatro. Principalmente por causa dessa coisa da personalidade (GF).

De acordo com estes excertos das narrativas de Noah, é possível perceber que, apesar da satisfação e felicidade por ter conquistado a retificação de seus documentos, há ainda outros fatores que são decisivos para o seu processo de transição. O que indica que a alteração do nome e do gênero nos documentos deve ser seguida da garantia de inclusão das pessoas trans na sociedade, sem que elas sejam expostas a mecanismos de controle que promovam a manutenção de valores e padrões normativos, restringindo ou direcionando os modos possíveis de se constituírem como sujeitos.

É preciso pensar em formas que: 1. possibilitem que Luis não precise passar pelo constrangimento de ter em seus documentos um carimbo com o lembrete de que ele está usando um "nome social", mesmo depois de ter uma sentença judicial autorizando a mudança de seu nome civil; 2 . possibilitem que Lucas não seja inserido em um universo em que práticas machistas são aceitas e naturalizadas ao buscar ser reconhecido socialmente como homem; 3. garantam que Silvio possa ser chamado por sua mãe pelo nome com o qual se reconhece, sem que fatores biologizantes ou memórias relacionadas ao seu pai o oprimam; 4. deem a oportunidade a Noah de continuar a estudar e começar a trabalhar com a confiança e a autoestima que tanto busca.

Lucas, Luis, Silvio e Noah Mathias já conquistaram judicialmente o direito de utilizar o nome pelo qual se reconhecem, agora, outros desafios precisarão ser superados neste processo de se subjetivarem como homens.

\section{TECENDO ALGUMAS CONSIDERAÇÕES}

Certos leitores queer consideram, por exemplo, o direito como o inimigo número 1, pois, ao impor suas categorias, ele impediria a emergência de novas subculturas. Entretanto, queer ou não, estamos todos presos a um conjunto de normas com as quais temos que lidar. Podemos não querer uma instituição e que sua própria existência funcione para nós. Podemos também transformar as normas jurídicas pela prática: por exemplo, ser casado e não viver juntos ou não ter uma definição estrita de fidelidade. Como Maggie Nelson escreve, as vidas queer são plenas de contradições, ao mesmo tempo ordinárias e extraordinárias (PERREAU, 2018, s/p).17

Em entrevista publicada no jornal Libération em 11 de maio de 2018, Bruno Perreau, autor de livros relacionados à temática queer na França, aponta que alguns/algumas estudiosos/as dessa teoria criticam a utilidade do Direito no processo de emergência de novas subculturas, entre as quais localizam-se também as identidades dos sujeitos transgêneros. Isto adviria do fato de que historicamente o Direito vem sendo o reduto de exclusões, atuando como produtor e reprodutor de lugares e posições de

\footnotetext{
${ }^{17}$ RESISTA! "Queer ou não, estamos todos presos a um conjunto de normas com as quais temos que lidar". Disponível em: https://resistaorp.blog/2018/07/10/queer-ou-nao-estamos-todos-presos-a-um-conjunto-de-normas-com-as-quais-temos-que-lidar/. Acesso em: 15 jul. 2018.
} 
gênero, entretanto, como o mesmo autor propõe, o que podemos fazer na condição de indivíduos queer é transformar as normas jurídicas que vêm delimitando os espaços e os modos possíveis dos sujeitos existirem.

Nesse sentido, provocar o Judiciário para que reconheça as identidades trans, modificando a forma com a qual as instituições jurídicas até então vêm atuando, promove algumas rupturas na normatividade hegemônica. Desse modo, o Direito pode servir como uma ferramenta de luta para os sujeitos que buscam o reconhecimento de suas identidades e não apenas como um instrumento que, atrelado à norma, subtraia toda e qualquer possibilidade de resistência e potência de criação.

Nesta pesquisa, como exemplo dessas reivindicações dos sujeitos transgêneros, estão os caminhos trilhados por Lucas, Luis, Silvio e Noah Mathias em busca de um nome. Um processo que perpassou a construção dos documentos de nome social que, ao mesmo tempo que se desvelou como "estratégia de inclusão, não resolveu definitivamente os problemas cotidianos enfrentados por quem continua a apresentar o nome de registro nos documentos oficiais" (AVILA, 2014, p. 73).

Como se verificou nesta pesquisa, o processo de reconhecimento como um sujeito pertencente a um gênero diferente daquele designado no nascimento, perpassou diferentes instâncias sociais, nas quais padrões normativos agiram para condicionar os modos possíveis de constituição do sujeito na sociedade.

Nesse sentido, os sujeitos transgêneros entrevistados narraram que, quando possuíam apenas a carteira de nome social, a eles era relegado apenas um espaço restrito, cheio de constrangimento e exclusão, uma vez que a autoidentificação como sujeitos pertencentes a um gênero diferente daquele designado no nascimento não representava o reconhecimento social que buscavam. Para se constituírem como sujeitos masculinos, foi necessário que buscassem, por meio de uma sentença judicial - i. e.: uma imposição da lei - o reconhecimento da sociedade [que, como se sabe, a partir de Butler, condiciona a formação do sujeito (BUTLER, 2005).

Por meio da decisão do Estado, favorável à retificação de seus documentos, estes sujeitos conseguiram maior reconhecimento social em suas famílias e espaços de convivência, dando um passo adiante no processo de subjetivação como homens. Uma série de atributos socialmente considerados como masculinos Ihes foram conferidos, como "força", "virilidade", ou mesmo a inserção em um ambiente considerado machista.

Torna-se evidente, nestes casos estudados, que os movimentos realizados por ativistas sociais, pesquisadores/as, educadores/as e Judiciário, têm possibilitado a atenção às demandas dos sujeitos transgêneros, entre as quais incluem-se hospitais especializados na atenção a estes sujeitos, bem como a recente decisão do Supremo Tribunal Federal que possibilitou que pessoas trans pudessem alterar o nome e o gênero no registro civil em cartórios. ${ }^{18}$

${ }^{18}$ CARTA CAPITAL. Trans poderão mudar de nome no registro civil sem cirurgia, decide STF. Disponível em: https:// www.cartacapital.com.br/diversidade/trans-poderao-mudar-de-nome-no-registro-civil-sem-cirurgia-decide-stf. Acesso em: 21 maio 2018. 
Tudo isto favorece as pessoas na ocupação de espaços que até pouco tempo thes eram negados, como escolas, mercado de trabalho e espaços políticos, por exemplo. Sendo assim, para o pleno acesso de direitos, faz-se pertinente que as conquistas legais sejam efetivadas.

Com efeito, o processo de legitimação do nome a partir de uma decisão proferida pelo Estado posicionou e legitimou esses indivíduos como sujeitos masculinos. Sem sombra de dúvidas, o conjunto de discursos e práticas que compõe a luta judicial pela retificação de um nome pelo qual se reconheçam atua substancialmente na constituição subjetiva das pessoas trans, representando um marcador que, ainda que não seja decisivo, é mais um passo adiante.

\section{REFERÊNCIAS}

ÁVILA, Simone Nunes. FTM, transhomem, homem trans, trans, homem: a emergência de transmasculinidades no Brasil contemporâneo. 2014. Tese (Doutorado) - Universidade Federal de Santa Catarina, Centro de Filosofia e Ciências Humanas, Programa de Pós-Graduação Interdisciplinar em Ciências Humanas, 2014.

BENTO, Berenice Alves de Melo. O que é transexualidade. São Paulo: Brasiliense, 2008.

BENTO, Berenice Alves de Melo. A reinvenção do corpo: sexualidade e gênero na experiência transexual. Rio de Janeiro: Garamond, 2006.

BENTO, Berenice Alves de Melo. A campanha internacional de ação pela despatologização das identidades trans: entrevista com o ativista Amets Suess. Revista Estudos Feministas. Florianópolis, v. 20, n. 2, p. 481-484, 2012. Disponível em: http://www.scielo.br/scielo.php?script=sci_arttext\&pi$\mathrm{d}=$ S0104-026X2012000200008\&lng=en\&nrm=iso. Acesso em: 25 jun. 2018.

BENTO, Berenice Alves de Melo. Nome social para pessoas trans: cidadania precária e gambiarra legal. Contemporânea, v. 4, n. 1 p. 165-182, 2014.

BUTLER, Judith. El género en disputa. Médico: Paidós, 2001.

BUTLER, Judith. Problemas de gênero. Feminismo e subversão da identidade. Rio de Janeiro: Civilização Brasileira, 2003. 236 p.

BUTLER, Judith. Cuerpos que importan - sobre los límites materiales y discursivos del "sexo". Buenos Aires: Paidós, 2005.

BUTLER, Judith. Deshacer el género. Barcelona: Paidós, 2006.

BUTLER, Judith. "Como os corpos se tornam matéria: entrevista com Judith Butler". Entrevista concedida a Baukje Prins e Irene Costera Meijer. In: Revista Estudos Feministas, Florianópolis, v. 10, n. 1, p. 155-167, jan. 2002.

BUTLER, Judith. Corpos que pesam: sobre os limites discursivos do "sexo". In: LOURO, Guacira Lopes (org.). O corpo educado: pedagogias da sexualidade. 2. ed. Belo Horizonte: Autêntica, 2000. p. 151-172.

CARTA CAPITAL. Trans poderão mudar de nome no registro civil sem cirurgia, decide STF. Disponível em: https://www.cartacapital.com.br/diversidade/trans-poderao-mudar-de-nome-no-registro-civil-sem-cirurgia-decide-stf. Acesso em: 21 maio 2018.

CONNELLY, Michael; CLANDININ, Jean. Relatos de experiencia e investigación narrativa. In: LARROSA, Jorge. Déjame que te cuente. Barcelona: Laertes, 1995. p. 11-59.CORREA, Crishna Mirella de Andrade. Subjetividades em trânsito: nome social, travestilidades e transexualidades em duas Universidades Públicas do Sul do Brasil. 2017. Tese (Doutorado) - Universidade Federal de Santa Catarina, Centro de Filosofia e Ciências Humanas, Programa de Pós-Graduação Interdisciplinar em Ciências Humanas, Florianópolis, 2017.

DUQUE, Tiago. Gêneros incríveis: identificação, diferenciação e reconhecimento no ato de passar por. 2013. Tese (Doutorado) - Programa de Pós-Graduação em Ciências Sociais, Universidade Estadual de Campinas, Campinas, 2013.

FLORES, Maicon Varella; DIAS, Renato Duro; BRUM, Amanda Netto. Alteração do registro civil de transexuais: uma análise empírica do posicionamento do TJ/RS. In: Revista de Estudos Empíricos em Direito Brazilian Journal of Empirical Legal Studies, São Paulo, v. 4, n. 2, p. 39-54, jun. 2017. 
GOELLNER, Silvana Vilodre. A produção cultural do corpo. In: LOURO, Guacira Lopes; FELIPE, Jane; GOELLNER, Silvana Vilodre (org.). Corpo, gênero e sexualidade: um debate contemporâneo na educação. 9. ed. Petrópolis, RJ: Vozes, 2013. p. 1-8.

HALL, Stuart. Quem precisa da identidade? In: SILVA, Tomaz Tadeu (org. e trad.). Identidade e diferença: a perspectiva dos estudos culturais. Petrópolis: Vozes, 2000.

LARROSA, Jorge. Narrativa, Identidad e Desidentificación. In: LARROSA, Jorge. La Experiência de la Lectura: estudios sobre literatura e formación. Barcelona: Laertes, 1996. p. 461-482.LARROSA, Jorge. Tecnologias do eu e educação. In: SILVA, Tomaz Tadeu. O sujeito da educação. Petrópolis: Vozes, 1994. p. 35-86.

LOURO, Guacira Lopes. Gênero, sexualidade e educação: uma perspectiva pósestruturalista. 10. ed. Petrópolis: Vozes, 2008.

LOURO, Guacira Lopes. Um corpo estranho - ensaios sobre sexualidade e teoria queer. Belo Horizonte: Autêntica, 2004. 92 p.

LOURO, Guacira Lopes. Um corpo estranho. Belo Horizonte: Autêntica, 2013.

MISKOLCI, Richard. Não somos, queremos: reflexões queer sobre a política sexual brasileira contemporânea. In: COLLING, Leandro (org.). Stonewall 40 + o que no Brasil? Salvador: Edufba, 2011. p. 37-56.

PEREIRA, Pedro Paulo Gomes. Corpo, Sexo e Subversões: reflexões sobre duas teorias queer. Interface Comunicação, Saúde, Educação, v. 12, n. 26, p. 499-512, 2008. Disponível em: http://www.scielo.br/scielo.php?script=sci_arttext\&pid=S1414-32832008000300004\&Ing=en\&nrm=is. Acesso em: 26 jun. 2018.

PINO, Nádia Perez. A teoria queer e os intersex: experiências invisíveis de corpos desfeitos. Cadernos Pagu, Campinas, n. 28, p. 149-174, jan./jun. 2007. Disponível em: http://www.scielo.br/pdf/cpa/n28/08. pdf. Acesso em: 26 jun. 2016.

QUEIROZ, Gustavo Lemes de; ALMEIDA, Victor Afonso. O que é nome social? In: RAMOS, Marcelo Maciel; NICOLI, Pedro Augusto Gravatá; BRENER, Paula Rocha Gouvêa (org.). Gênero, sexualidade e direito: uma introdução. Belo Horizonte: Initia Via, 2006. p. 246-255.

RESISTA! "Queer ou não, estamos todos presos a um conjunto de normas com as quais temos que lidar". Disponível em: https://resistaorp.blog/2018/07/10/queer-ou-nao-estamos-todos-presos-a-um-conjunto-de-normas-com-as-quais-temos-que-lidar/. Acesso em: 15 jul. 2018.

RIOS, Roger Raupp; OLIVEIRA, Rosa Maria Rodrigues de. "Direitos sexuais e heterossexismo: identidades sexuais e discursos judiciais no Brasil”. In: MISKOLICI, Richard; PELÚCIO, Larissa (org.). Discursos fora da ordem: sexualidades, saberes e direitos. São Paulo: Annablume, 2012. p. 245-276.

SANTOS, Dayana Brunetto Carlin dos. A biopolítica educacional e o governo de corpos transexuais e travestis. Cadernos de Pesquisa, São Paulo, v. 45, n. 157, p. 630-651, jul./set. 2015.

SANTOS, Lohana Morrelli Tanure. O que é transexualidade. In: RAMOS, Marcelo Maciel; NICOLI, Pedro Augusto Gravatá; BRENER, Paula Rocha Gouvêa (org.). Gênero, sexualidade e direito: uma introdução. Belo Horizonte: Initia Via, 2016. p. 108-115.

SILVA, Tomaz Tadeu. Documentos de identidade: uma introdução às teorias do currículo. 2. ed. 11a. imp. Belo Horizonte: Autêntica, 2007. 